Research Paper

\title{
Risk Factors of Myopic Shift among Primary School Children in Beijing, China: A Prospective Study
}

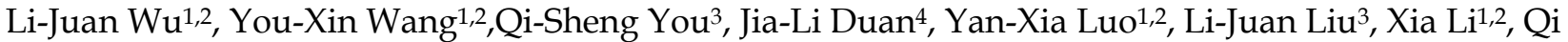

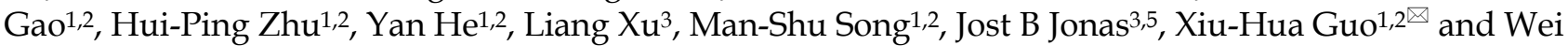 Wang $1,2,6 \bowtie$}

1. School of Public Health, Capital Medical University, Beijing 100069, China

2. Municipal Key Laboratory of Clinical Epidemiology, Capital Medical University, Beijing 100069, China

3. Beijing Institute of Ophthalmology, Beijing Tongren Eye Center, Beijing Tongren Hospital, Capital Medical University, Beijing Ophthalmology and Visual Science Key Lab, Beijing100005, China

4. Beijing Center for Disease Prevention and Control, Beijing 100013, China

5. Department of Ophthalmology, Medical Faculty Mannheim of the Ruprecht-Karls-University Heidelberg, 68167 Mannheim, Germany

6. School of Medical Science, Edith Cowan University, Perth 6027, Australia

$\triangle$ Corresponding authors: Prof. Wei Wang, School of Public Health, Capital Medical University. Beijing 100069, China. Tel: +861083911508; Fax: +861083911508; E-mail: wei.wang@ecu.edu.au or Prof. Xiu-Hua Guo, School of Public Health, Capital Medical University, Beijing 100069, China. E-mail: guoxiuh@ccmu.edu.cn

(c) 2015 Ivyspring International Publisher. Reproduction is permitted for personal, noncommercial use, provided that the article is in whole, unmodified, and properly cited. See http:/ /ivyspring.com/terms for terms and conditions.

Received: 2015.03.14; Accepted: 2015.07.06; Published: 2015.07.25

\begin{abstract}
Objective: To evaluate factors associated with myopic shift among primary school children.

Methods: In a one-year prospective school-based study, 5052 children from ten schools were enrolled using a multi-stage random cluster approach. The baseline examination included non-cycloplegic auto-refractometry and questionnaire interview. Measurements were repeated at the follow-up.

Results: Among 5052 students at baseline investigated, 4292 students (85.0\%) returned for the follow-up examination. The mean refractive error ( $-1.13 \pm 1.57$ diopters) had changed $-0.52 \pm 0.73$ diopters from the baseline to the follow-up examination. $2170(51.0 \%)$ had a rate of significant myopic shift (significant myopic shift is defined as the change of spherical equivalent of the refraction $\leq-0.50 \mathrm{D}$ between the follow-up and baseline measures). We confirmed that common associated factors (older age, parental myopia, lower refractive status at baseline, shorter reading distance and lower frequency of outdoor activities during class recesses) were associated with greater shift towards myopia. After controlling for age, sex, region of habitation, parental myopia and refractive status at baseline, greater shift towards myopia was independently associated with distance from near-work $(\mathrm{OR}=1.48,95 \% \mathrm{Cl}=1.26-1.74, P<0.001)$ and longer time outdoors for leisure $(\mathrm{OR}=0.87,95 \% \mathrm{Cl}=0.78-0.97, P<0.013)$.

Conclusion: Greater shift towards myopia was independently associated with modifiable factors (distance from near-work and longer time outdoors for leisure) might suggest that encouraging children to go outside for outdoor activities during class recess and after school may be a promising and feasible intervention against myopia development.
\end{abstract}

Key words: Myopic shifts, Risk factors, Primary school children, Myopia, Beijing China.

\section{Introduction}

Myopia has emerged as a major global public health issue, particularly in East Asia ${ }^{[1]}$. Around $80 \%$ or more of young adults have myopia in East Asian countries including Mainland China, Taiwan and Korea [2-4]. The economic cost and medical burden of myopia are also high. In Singapore, the direct cost of myopia for each school child was estimated to be US $\$ 148$ [5]. Myopia, in particular high myopia may increase the risk of uncorrectable visual impairment (open angle glaucoma, retinal detachment and cata- 
ract) and even blindness in later life [6-9].

From a series of clinical perspective studies, the efficiency of intervention to slow down the progression of myopia is limited. A meta-analysis of 11 randomized clinical trials showed that the optical treatment is not effective for myopia control [10]. Anti-muscarinic drugs such as atropine eye drops has been found to be effective in reducing the progression of myopia, while the risk of side effects such as photophobia, decreased near vision, dry eye, flushed skin etc is high [10]. Therefore, it is important to identify modifiable risk factors of myopia that can help us to slow or stop myopia progression.

Several longitudinal studies have investigated the relationship between near-work activities and myopia development or progression. However, these studies have produced inconsistent results [11-14]. Two studies found an association between excessive near-work and refractive error change toward myopia [11-12], whereas the other two studies did not support that there exists any effects of near-work on myopia progression [13-14]. Recent epidemiology surveys have shown that increased amounts of time outdoors protect against the development of myopia. Four longitudinal studies have shown associations between more time spent in outdoor activity and reduction of risk in development of myopia [15-18]. A refractive change toward myopia was also found in the group with less outdoor activities [11,12]. However, three other longitudinal studies did not observed the relationship between outdoor activities and the progression of myopia $[13,19,20]$.

The conflict results of the previous studies, therefore, show limited supports that more time in near-work and less time outdoor activity increase the incidence of myopia. The purpose of the present study is to explore the risk factors for myopia shift, particularly the modifiable risk factors such as near-work and outdoor activity, and myopia progression.

\section{Methods}

\section{Participants}

The study was approved by the respective ethics committees of Capital Medical University, the Beijing Municipal Commission of Education and the Beijing Center for Disease Control and Prevention. It followed the Declaration of Helsinki. Written consent was obtained from the parents of all participants.

This school-based study was initially carried out in November 2010. Sampling was performed using multi-stage random cluster approach. In the first step, five districts were randomly selected from all 16 districts in the rural and urban regions of Beijing. In the second step, two schools were randomly selected from each of the five selected districts. In the third step, all students of grade 1 to 5 of the selected schools with age of 6-12 years were sampled. The exclusion criteria were the followings: 1) Children who reported eye conditions within the last month (e.g., eye injuries, mild conjunctivitis or "red eye", hordeolum, keratitis or corneal irritation, dry eye syndrome, glaucoma; 2) Parents refused to sign the informed consents. The follow-up examinations were performed one year later in November 2011 after the baseline survey.

\section{Interview and follow-up}

At baseline and follow-up examinations, all students and their parents completed a detailed questionnaire firstly. The quality of the interview was controlled by school physicians and head teacher in each class.

The questionnaire included two parts. The first part of the questionnaire was filled in by the children and assisted by their parents. For very young children who could not read or understand the questionnaire very well (e.g., the youngest children of 6 years old), help was sought from their parents. Basic socio-demographic data, such as age, sex, ethnic background, region of habitation (urban/rural), was included in the first part of the questionnaire. In the second part, information of parents' myopia was obtained by asking the parents' question "Does children's father/mother have myopia".

The first part of the questionnaire additionally included questions on near-work activities such as the amount of time spent on studying or watching television and on computer activities per day; questions on the average reading distance (closer than $33 \mathrm{~cm}$ (equivalent to one "chi" as a Chinese length unit), or $\geq 33 \mathrm{~cm}$ ), the average distance in working with a computer (closer than $66 \mathrm{~cm}$ (equivalent to two "chi") or $\geq 66 \mathrm{~cm}$ ), and the average distance to the television set (closer than $2.5 \mathrm{~m}$, or $\geq 2.5 \mathrm{~m}$ ). The total time of near-work per day (defined as the time spent for studying plus time spent for watching television and computer activities) and the distance at which nearwork was carried out were assessed. If the average reading distance and the average distance in computer activities was $\geq 33 \mathrm{~cm}$ and if the distance to the television set was $\geq 2.5 \mathrm{~m}$, the distance was overall classified as adequate. Otherwise, the distance was classified as "close". We also inquired whether the students had an active rest during their studying periods. The active rest during studying was defined as the students purposely looking far into the distance for ten minutes every 40-50 minutes during their studying periods. It was graded as "occasional" $(\leq 5$ times every day), "common" (6-10 times every day), and "often" ( $\geq 11$ times every day). 
The first part of the questionnaire also include questions about outdoor activities such as how long the children spent in outdoor activities for leisure (such as playing outdoors and walking.) during class recess; how long the children spent on outdoor activities for leisure after school; how long the children spent on outdoor activities for leisure during weekends; how long the children spent on sports during week and weekend. The average time of daily outdoor activity for leisure was calculated using the formula: [(hours spent during class recess + hours spent after school) $\times 5+$ (hours spent in weekend days) $\times 2] / 7$. The average time of daily sport was calculated using the formula: [(hours spent on weekdays) $\times 5+$ (hours spent in weekend days) $\times 2] / 7$.

After the interview, ophthalmological examinations were performed on the school premises by two trained optometrists. Non-cycloplegic auto-refractometry (Topcon RM-A7000; Topcon Co., Tokyo, Japan) was carried out by a senior experienced optometrist. The mean of three readings were taken.

The data were analyzed using a commercially available statistical program (SPSS for Windows, version 21.0; IBM-SPSS, Chicago, Illinois, USA). The spherical equivalent of the refraction (SER) was calculated as the spherical refractive error plus half of the minus cylindrical refractive error. As the SER of the right and left eyes were well correlated (Spearman's correlation coefficient $=0.809$ ), only the data for the right eye is presented. The shift in refraction was determined by the difference of mean SER between the follow-up and baseline measures. As auto refractors rounded up refractive measures to the nearest $0.12 \mathrm{D}$ in either direction, there may be a measurement error of $0.25 \mathrm{D}$ at each point of examination. So, the significant myopic shift was defined as change of SER $\leq$ $-0.50 \mathrm{D}$. To examine the possible impacts of nonparticipation at follow-up examination and relationship between the significant myopic shift with other parameters at baseline (univariate analysis), $\chi^{2}$ test was used to evaluate the differences in proportions for nominal variables; and Wilcoxon rank test was used to evaluate difference for ordinal variables (such as parental myopia) or continuous variables with abnormal distribution. Multiple logistic regression analysis was then used to determine independent factors associated with significant myopic shift. Odds ratios (OR) and 95\% Confidence Interval (95\% CI) were calculated. All $P$-values were 2 -sided and considered statistically significant when less than 0.05 .

\section{Results}

In $2011,4292(85.0 \%$ of the 5052 students examined at baseline) participants returned for the follow-up examination. Socio-demographic characteris- tics were compared between those children who participated in both examinations and those lost to follow-up (Table 1). The children who participated in the follow-up examination were more likely to be male $(P<0.001)$ and have lower refractive status at baseline $(P=0.026)$ than those lost to follow-up. There was no difference in socio-demographic factors, including age $(P=0.396)$, and region of habitation $(P=0.357)$ between children who retained in the study and those lost to follow-up. There was also no differences in parental myopia between the two groups $(P=0.066)$. In 2010, the mean age of the 4292 eligible children was $8.47 \pm 1.54$ years (range: $6-12$ years) with $49.2 \%$ of them were females; $40.7 \%$ of them living in urban.

In 2011 survey, the mean refractive error (-1.13 \pm 1.57 diopters) had changed by $-0.52 \pm 0.73$ diopters. $2170(51.0 \%)$ had a rate of significant myopic shift (SER $\leq-0.5 \mathrm{D}$ between the follow-up and the baseline) (Figure 1).

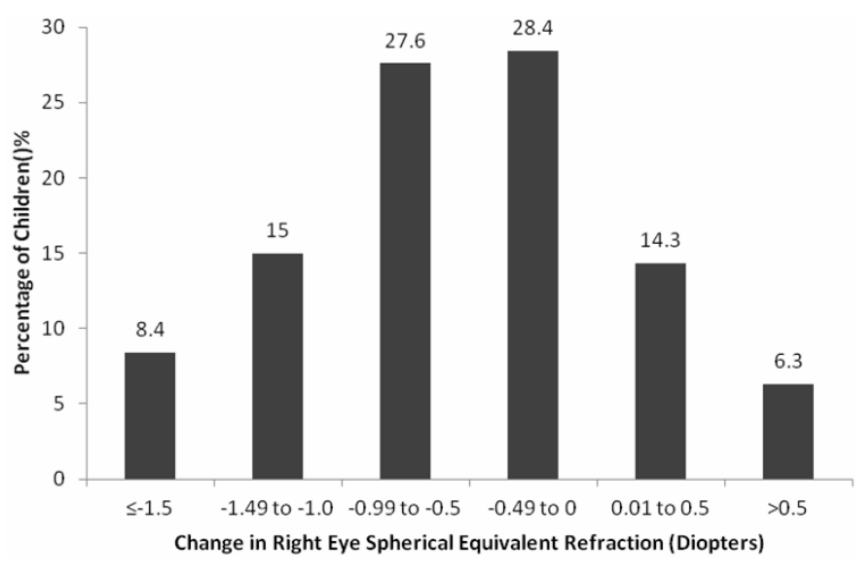

Figure 1. Change in right eye spherical equivalent refraction in one-year follow-up for children in primary schools.

Table 1. Comparisons of demographics, refractive status, near-work and outdoor activities at baseline between those children who participated in both examinations and those lost in follow-up.

\begin{tabular}{|c|c|c|c|}
\hline Characteristic & In follow-up & Lost in follow-up & $P$ \\
\hline Age (years) & $8.47 \pm 1.54$ & $8.44 \pm 1.53$ & 0.396 \\
\hline \multicolumn{4}{|l|}{$\operatorname{Sex} n(\%)$} \\
\hline Male & 2089(50.8) & $370(48.7)$ & $<0.001$ \\
\hline Female & 2021(49.2) & $337(44.3)$ & \\
\hline \multicolumn{4}{|l|}{ Region of Habitation n (\%) } \\
\hline Rural & $2538(59.3)$ & $464(61.1)$ & 0.357 \\
\hline Urban & $1744(40.7)$ & $296(38.9)$ & \\
\hline \multicolumn{4}{|l|}{ Parental Myopia n (\%) } \\
\hline Both Not Myopic & $2315(55.5)$ & $375(51.2)$ & 0.066 \\
\hline $\begin{array}{l}\text { Father or Mother } \\
\text { Myopic }\end{array}$ & $1325(31.8)$ & $249(34.0)$ & \\
\hline Both Myopic & $528(12.7)$ & 109(14.9) & \\
\hline $\begin{array}{l}\text { Refractive Error of Right } \\
\text { Eye (Diopters) }\end{array}$ & $-0.61 \pm 1.30$ & $-0.55 \pm 1.40$ & 0.026 \\
\hline
\end{tabular}


In univariate analysis, greater shift towards myopia was associated with older age $(P<0.001)$, female $(P=0.049)$, urban region $(P<0.001)$, parental myopia $(P<0.001)$, lower refractive status at baseline $(P<0.001)$, shorter time outdoors for leisure $(P<0.001)$, shorter distance from near-work $(P<0.001)$, whereas not with time outdoors for sports $(P=0.154)$, time spent for near-work $(P=0.400)$, and active rest during study $(P=0.061)$ (Table 2$)$.

Table 2. Associations (univariate analysis) between the significant myopic shift (defined as of right eye spherical equivalent refraction (SER) $\leq-0$. 50D change between follow-up and baseline within one year) and associated factors in primary school children

\begin{tabular}{|c|c|c|c|}
\hline & $\begin{array}{l}\text { SER } \leq-0.50 \mathrm{D} \\
\text { Change }\end{array}$ & $\begin{array}{l}\text { SER }>-0.50 \mathrm{D} \\
\text { Change }\end{array}$ & $\begin{array}{l}P \\
\text { value }\end{array}$ \\
\hline Age (Years) & $8.65 \pm 1.51$ & $8.29 \pm 1.56$ & $<0.001$ \\
\hline \multicolumn{4}{|l|}{ Sex $n(\%)$} \\
\hline Male & $1025(49.7)$ & $1038(50.3)$ & 0.049 \\
\hline Female & $1057(52.8)$ & $946(47.2)$ & \\
\hline \multicolumn{4}{|l|}{ Region of Habitation $\mathrm{n}(\%)$} \\
\hline Rural & $1193(47.6)$ & $1312(52.4)$ & $<0.001$ \\
\hline Urban & $977(56.4)$ & $754(43.6)$ & \\
\hline \multicolumn{4}{|l|}{ Parental Myopia n(\%) } \\
\hline Both Not Myopic & $1041(45.5)$ & $1249(54.5)$ & $<0.001$ \\
\hline Father Myopic or Mother Myopic & $707(53.9)$ & $604(46.1)$ & \\
\hline Both Myopic & $352(67.3)$ & $171(32.7)$ & \\
\hline $\begin{array}{l}\text { Refractive Error of Right Eye at Base- } \\
\text { line (Diopters) }\end{array}$ & $-0.88 \pm 1.48$ & $-0.33 \pm 1.00$ & $<0.001$ \\
\hline $\begin{array}{l}\text { Time Outdoors for Leisure } \\
\text { (Hours/Day) }\end{array}$ & $1.03 \pm 0.65$ & $1.40 \pm 0.70$ & $<0.001$ \\
\hline $\begin{array}{l}\text { Time Outdoors for Sports (Hours/ } \\
\text { Day) }\end{array}$ & $0.89 \pm 0.61$ & $0.86 \pm 0.66$ & 0.154 \\
\hline $\begin{array}{l}\text { Time Spent for Near-Work } \\
\text { (Hours/Day) }\end{array}$ & $7.74 \pm 2.93$ & $7.68 \pm 3.02$ & 0.400 \\
\hline \multicolumn{4}{|l|}{ Distance from Near-Work n (\%) } \\
\hline Adequate & $379(43.3)$ & $497(56.7)$ & $<0.001$ \\
\hline Close & $1616(53.4)$ & $1412(46.6)$ & \\
\hline \multicolumn{4}{|l|}{ Active Rest During Study } \\
\hline Often & $900(49.2)$ & $931(50.8)$ & 0.061 \\
\hline Common & $622(53.0)$ & $552(47.0)$ & \\
\hline Occasionally & $648(52.6)$ & $583(47.4)$ & \\
\hline
\end{tabular}

In model 1 (Table 3), after controlling for sex and age, greater shift towards myopia was significantly associated with distance from near-work $(\mathrm{OR}=1.58$, 95\% CI=1.35-1.85, $P<0.001)$, higher refractive status at baseline $(\mathrm{OR}=0.72,95 \% \mathrm{CI}=0.68-0.76, P<0.001)$, longer time outdoors for leisure $(\mathrm{OR}=0.85,95 \% \mathrm{CI}=0.77-0.94$, $P=0.002)$, higher frequency of active rest during study (OR=0.86, 95\% CI=0.74-0.99, $P=0.042$ ), but not with time outdoors for sports $(\mathrm{OR}=1.09,95 \% \mathrm{CI}=0.97-1.22$, $P=0.135)$, and time spent for near-work (OR=1.00, $95 \%$ $\mathrm{CI}=0.98-1.02, P=0.935)$.

In Model 2 (adjusting for age, sex, and region of habitation), greater shift towards myopia remained significantly associated with distance from near-work (OR=1.56, 95\% CI=1.34-1.83, $P<0.001)$, higher refractive status at baseline $(\mathrm{OR}=0.72,95 \% \mathrm{CI}=0.68-0.76$,
$P<0.001)$, longer time outdoors for leisure $(\mathrm{OR}=0.85$, $95 \% \mathrm{CI}=0.77-0.95, P=0.003)$. Higher frequency of active rest during study lose statistical significance $(\mathrm{OR}=0.87,95 \% \mathrm{CI}=0.75-1.01, \quad P=0.065)$. Significant myopic shift was not associated with time outdoors for sports, and time spent for near-work (Table 3).

In model 3 adjusting for age, sex, region of habitation and parental myopia, greater shift towards myopia was still associated with distance from near-work $(\mathrm{OR}=1.51,95 \% \mathrm{CI}=1.29-1.78, \quad P<0.001)$, higher refractive status at baseline $(\mathrm{OR}=0.75,95 \%$ $\mathrm{CI}=0.70-0.79, P<0.001)$, and longer time outdoors for leisure (OR=0.86, 95\% CI=0.77-0.96, $P=0.005)$. Greater shift towards myopia was not significantly associated with active rest during study, time outdoors for sports, and time spent for near-work (Table 3). In the last model controlling for age, sex, region of habitation, parental myopia and refractive status at baseline, significant myopia was associated with distance from near-work $(\mathrm{OR}=1.48,95 \% \mathrm{CI}=1.26-1.74, P<0.001)$ and longer time outdoors for leisure $(\mathrm{OR}=0.87,95 \%$ $\mathrm{CI}=0.78-0.97, P<0.013$ ) (Table 3).

Analysis of collinearity showed a variance inflation factor of less than 1.15, suggesting that inter-dependency of the variables did not markedly affect the results of the analysis.

\section{Discussion}

In the longitudinal follow-up analysis, older age, parental myopia, lower refractive status at baseline, shorter reading distance and lower frequency of outdoor activities during class recess was shown to be associated with greater shift towards myopia. The present study showed that greater shift towards myopia is associated with older age, female, parental myopia, lower refractive status at baseline, shorter distance from near-work and shorter time outdoors for leisure, but not with time outdoors for sports, time spent for near-work, active rest during study in univariate analysis. In logistic regression after controlling for age, sex, region of habitation, parental myopia and refractive status at baseline, greater shift towards myopia was associated with distance from near-work $(\mathrm{OR}=1.48,95 \% \mathrm{CI}=1.26-1.74, P<0.001)$ and longer time outdoors for leisure $(\mathrm{OR}=0.87,95 \% \mathrm{CI}=0.78-0$. 97, $P<0.013$ ).

The finding of greater shift towards myopia is associated with distance from near-work in this study is consistent with the findings in Australia that children who performed near-work at a distance of less than $30 \mathrm{~cm}$ are 2.5 times more likely to have myopia than those who worked at a longer distance ${ }^{[21]}$. Similar findings were reported from the military conscripts in Taiwan ${ }^{[22] .}$ 
Table 3. Modifiable associated factors of significant myopic shift (defined as of right eye spherical equivalent refraction (SER) $\leq-0$. 50D change between follow-up and baseline within one year) in primary school children in Beijing, China

\begin{tabular}{|c|c|c|c|c|c|c|c|c|}
\hline \multirow[t]{2}{*}{ Parameters } & \multirow{2}{*}{$\begin{array}{c}\text { Model } 1 \\
\text { OR }(95 \% \text { CI })\end{array}$} & \multicolumn{3}{|c|}{ Model 2} & \multirow{2}{*}{$\begin{array}{c}\text { Model } 3 \\
\text { OR }(95 \% \text { CI })\end{array}$} & \multicolumn{3}{|c|}{ Model 4} \\
\hline & & $P$ Value & OR $(95 \%$ CI $)$ & $P$ Value & & $P$ Value & OR $(95 \% \mathrm{CI})$ & $P$ Value \\
\hline $\begin{array}{l}\text { Refractive Error of Right Eye at Baseline } \\
\text { (Diopters) }\end{array}$ & $\begin{array}{c}0.72 \\
(0.68-0.76)\end{array}$ & $<0.001$ & $\begin{array}{c}0.72 \\
(0.68-0.76)\end{array}$ & $<0.001$ & $\begin{array}{c}0.75 \\
(0.70-0.79)\end{array}$ & $<0.001$ & - & - \\
\hline Time Outdoors for Leisure (Hours/Day) & $\begin{array}{c}0.85 \\
(0.77-0.94)\end{array}$ & 0.002 & $\begin{array}{c}0.85 \\
(0.77-0.95)\end{array}$ & 0.003 & $\begin{array}{c}0.86 \\
(0.77-0.96)\end{array}$ & 0.005 & $\begin{array}{c}0.87 \\
(0.78-0.97)\end{array}$ & 0.013 \\
\hline Time Outdoors for Sports (Hours / Day) & $\begin{array}{c}1.09 \\
(0.97-1.22)\end{array}$ & 0.135 & $\begin{array}{c}1.07 \\
(0.96-1.20)\end{array}$ & 0.218 & $\begin{array}{c}1.07 \\
(0.95-1.19)\end{array}$ & 0.268 & $\begin{array}{c}1.06 \\
(0.94-1.18)\end{array}$ & 0.353 \\
\hline Time Spent for Near Work (Hours/Day) & $\begin{array}{c}1.00 \\
(0.98-1.02)\end{array}$ & 0.935 & $\begin{array}{c}1.00 \\
(0.98-1.02)\end{array}$ & 0.814 & $\begin{array}{c}1.00 \\
(0.97-1.02)\end{array}$ & 0.749 & $\begin{array}{c}0.99 \\
(0.97-1.02)\end{array}$ & 0.993 \\
\hline \multicolumn{9}{|l|}{ Distance from Near Work n(\%) } \\
\hline Adequate & ref & & ref & & ref & & Ref & \\
\hline Close & $\begin{array}{c}1.58 \\
(1.35-1.85)\end{array}$ & $<0.001$ & $\begin{array}{c}1.56 \\
(1.34-1.83)\end{array}$ & $<0.001$ & $\begin{array}{c}1.51 \\
(1.29-1.78)\end{array}$ & $<0.001$ & $\begin{array}{c}1.48 \\
(1.26-1.74)\end{array}$ & $<0.001$ \\
\hline \multicolumn{9}{|l|}{ Active Rest During Study } \\
\hline Occasionally & ref & & Ref & & ref & & ref & \\
\hline Common & $\begin{array}{c}0.86 \\
(0.74-0.99)\end{array}$ & 0.042 & $\begin{array}{c}0.87 \\
(0.75-1.01)\end{array}$ & 0.065 & $\begin{array}{c}0.88 \\
(0.76-1.03)\end{array}$ & 0.884 & $\begin{array}{c}0.95 \\
(0.81-1.11)\end{array}$ & 0.520 \\
\hline Often & $\begin{array}{c}1.00 \\
(0.85-1.18)\end{array}$ & 0.984 & $\begin{array}{c}1.00 \\
(0.85-1.18)\end{array}$ & 0.999 & $\begin{array}{c}0.98 \\
(0.83-1.16)\end{array}$ & 0.977 & $\begin{array}{c}1.01 \\
(0.85-1.20)\end{array}$ & 0.892 \\
\hline
\end{tabular}

Model 1, controlling for sex, age; Model 2, controlling for sex, age, and regions; Model 3, controlling for sex, age, regions and parental myopia;

Model 4, controlling for sex, age, regions, parental myopia and refractive error of right eye at baseline (diopters).

In the multivariate analysis, there is no association between myopic shift and longer time spent in near work, which resembled to the other three longitudinal studies showing that reading hours per week was not related to myopia progression [13-15]. Interestingly, longer outdoor time for leisure was associated with greater shift towards myopia negatively. This is also consistent with the findings from the previous cross-sectional studies [23-28], and a longitudinal study which showed that an increase in myopia refractive error is significantly associated with less time spent in outdoors after adjustment for age [12].

However, we have not found any association between time spent in sports and significant myopic shift. This is consistent with a longitudinal study which showed that sport is not associated with less myopia progression from onset [13]. This also confirms our previous cross-sectional study which found that the sport is not associated with myopia [29].

In another study conducted by Jacobsen, physical activity was inversely associated with refractive error change toward myopia [11]. Our results agree with another four longitudinal studies which revealed that time spent in outdoors was predictive of incident myopia ${ }^{[15-18]}$. Our result further confirms the outcome of an interventional study, in which the interventions consisted of performing a recess outside the classroom (ROC) program that encouraged the children to go outside for outdoor activities during class recess. Outdoor activities during class recess in school have been proved to have significant effects on preventing myopic shift in non-myopic subjects [30].

A less hyperopic refraction at baseline is a strong predictor of greater shift towards myopia in our study. The odds for significant myopic shift increase with decreasing refractive status at baseline. This is in agree with findings from the Sydney Adolescent Vascular and Eye Study which showed that children with myopia at baseline are more likely to have a significant shift in refraction compared with children with no refractive error [17,31]. Our study is also consistent with the findings from the Orinda Longitudinal Study of Myopia which found refraction at baseline to be a strong predictor of the onset of juvenile myopia [32].

Our findings may have public health significances. A call named "one-hour sunshine sports movement" was issued by the China's Ministry of Education in 2006. The aim of the call is to promote students' physique health by encouraging students to have outdoor activities for at least one hour. The total daily recess time in school has been reached to 60 minutes (10, 30, 10 minutes in the morning and 10 minutes in afternoon). So, encouraging children to go outside for outdoor activities during class recess and after school may be a promising and feasible intervention against myopia development.

Our study has at least three limitations. Firstly, cycloplegia was not used in the present study. In our pilot investigation, we found some parents worried about the possible or potential side-effects. If cycloplegia is used, majority of parents will refuse to attend the study. Indeed non-cycloplegic refractometry may overestimate the prevalence of myopia in teenagers with active accommodation [33]. While we do not aim to explore the prevalence or incidence or progression of myopia, but focus to investigate the factors associated with myopic shift; therefore the weakness in this 
study is limited and may not markedly influence the results of our study. Secondly, the parameters of reading distance were self-reported and were not measured, and thus were inaccurate to a certain degree [34]. Thirdly, we used the Chinese length measure unit of "Chi" $(1 \mathrm{Chi}=33 \mathrm{~cm})$ which has been used for more than 3000 years in China and is only known to Chinese.

\section{Conclusion}

We confirmed that common associated factors (older age, parental myopia, lower refractive status at baseline, shorter reading distance and lower frequency of outdoor activities during class recesses) were associated with greater shift towards myopia. After controlling for age, sex, region of habitation, parental myopia and refractive status at baseline, greater shift towards myopia was independently associated with distance from near-work and longer time outdoors for leisure. Those findings suggest that encouraging children to go outside for outdoor activities during class recess and after school may be a promising and feasible intervention against myopia development.

\section{Acknowledgements}

The study was funded by the Project from Beijing Municipal Commission (PXM2011_014226_07_ 000110), the Natural Science Fund of China (81373099, 81370083, 81273170, 81172772), the National "12th Five-Year" Plan for Science and Technology, China (2012BAI37B03), Beijing Natural Science Foundation (7131002), Key Projects in the National Science \& Technology Pillar Program in the Twelfth Five-year Plan Period of China (2011BAI08B01), National S\&T Major Project (2012ZX10005009-003). YX Wang was supported by Beijing Higher Education Young Elite Teacher Project (YETP1671) and Beijing Nova Program (Z141107001814058) and W Wang was supported by the Importation and Development of High-Calibre Talents Project of Beijing Municipal Institutions.

\section{Competing interests}

The authors declare there are not conflicts of interest.

\section{References}

1. Morgan IG, Ohno-Matsui K. Saw SM. Myopia. Lancet. 2012; 379:1739-1748

2. Sun J, Zhou JB, Zhao PQ. et al. High prevalence of myopia and high myopia in 5060 chinese university students in Shanghai. Invest Ophthalmol Vis Sci. 2012; 53:7504-7509.

3. Lin LL, Shin YF, Hsiao CK, Chen CJ. Prevalence of myopia in Taiwanese schoolchildren: 1983-2000. Ann Acad Med. 2004; 33:27-33.

4. Jung SK, Lee JH, Kakizaki H, Jee D. Prevalence of myopia and its association with body stature and educational level in 19-year-old male conscripts in Seoul, South Korea. Invest Ophthalmol Vis Sci. 2012; 53:5579-5583.
5. Lim MC, Gazzard G, Sim EL, Tong L, Saw SM. Direct costs of myopia in Singapore. Eye. 2009; 23:1086-1089.

6. Marcus MW, d Vries MM, Junoy Montolio FG, Jansonius NM. Myopia as a risk factor for open-angle glaucoma: a systematic review and meta-analysis. Ophthalmology. 2011; 118:1989-1994.

7. Chou SC, Yang CH, Lee CH. et al. Characteristics of primary rhegmatogenous retinal detachment in Taiwan. Eye (Lond). 2007; 21(8):1056-1061.

8. Leske MC, Chylack LT, Wu SY. The lens opacities case-control study. Risk factors for cataract. Arch Ophthalmol. 1991; 109:244-251.

9. Saw SM, Gazzard G, Shih-Yen EC, Chua WH. Myopia and associated pathological complications. Ophthalmic Physiol Opt. 2005; 25:381-391.

10. Leo SW, Young TL. An evidence-based update on myopia and interventions to retard its progression. JAAPOS. 2011; 15:181-189.

11. Jacobsen $\mathrm{N}$, Jensen $\mathrm{H}$, Goldscbmidt E. Does the level of physical activity in university students influence development and progression of myopia? - A 2-year prospective cohort study. Invest Ophthalmol Vis Sci. 2008; 49(4):1322-1327.

12. Guo Y, Liu LJ, Xu L. et al. Myopic shift and outdoor activity among primary school children: one-year follow-up study in Beijing. PLoS One. 2013; 8(9):e75260.

13. Jones-Jordan LA, Sinnott LT, Cotter SA, Mitchell GL, Moeschberger ML, Zadnik K. Time outdoors, visual activity, and myopia progression in juvenile-onset myopes. Invest Ophthalmol Vis Sci. 2012; 53:7169-7175.

14. Saw SM, Nieto FJ, Katz J, Schein OD, Levy B, Chew SJ. Factors related to the progression of myopia in Singaporean children. Optom Vis Sci. 2000; 77:549-554.

15. Jones-Jordan LA, Sinnott LT, Mutti DO, Mitchell GL, Moeschberger ML, Zadnik K. Parental history of myopia, sports and outdoor activities, and future myopia. IOVS. 2007; 48(8):3524-3532.

16. Jones-Jordan LA, Mitchell GL, Cotter SA. et al. Visual activity before and after the onset of juvenile myopia. IOVS. 2011; 52(3):1841-1849.

17. French AN, Morgan IG, Mitchell P, Jee D. Risk factors for incident myopia in Australian schoolchildren. Ophthalmology. 2013; 120(10):2100-2108.

18. Guggenbeim JA, Nortbstone K, Mcmabon G. et al. Time outdoors and physical activity as predictors of incident myopia in childhood: a prospective cohort study. Invest Ophthalmol Vis Sci. 2012; 53(6):2856-2865.

19. Saw SM, Shankar A, Tan SB. et al. A cohort study of incident myopia in Singaporean children. Invest Ophthalmol Vis Sci. 2006; 47(5):1839-1844.

20. Huang CY, Hou CH, Lin KK, Lee JS, Yang ML. Relationship of lifestyle and body stature growth with development of myopia and axial length elongation in Taiwanese elementary school children. Indian J Ophthalmol. 2014; 62(8):865-869.

21. IP JM, Saw SM, Rose KA. et al. Role of near work in Myopia: Findings in a sample of Australian school children. Invest Ophthalmol Vis Sci. 2008; 49:2903-2910.

22. Lee Y, Lo CT, Sheu SJ, Lin JL. What factors are associated with myopia in young adults? A survey study in Taiwan military conscripts. Invest Ophthalmol Vis Sci. 2013; 54:1026-1033.

23. Mutti DO, Mitchell GL, Moeschberger ML, Jones LA, Zadnik K. Parental myopia, near work, school achievement and children's refractive error. Invest Ophthalmol Vis Sci. 2002; 43:3633-3640.

24. Rose KA, Morgan IG, Smith W. et al. Myopia, lifestyle, and schooling in students of Chinese ethnicity in Singapore and Sydney. Arch Ophthalmol. 2008; 126:527-530

25. Saw SM, Zhang MZ, Hong RZ, Fu ZF, Pang MH, Tan DT. Near-work activity, night-lights, and myopia in the Singapore-China study. Arch Ophthalmol. 2002; 120:620-627.

26. Rose KA, Morgan IG, IP J. et al. Outdoor activity reduces the prevalence of myopia in children. Ophthalmology. 2008; 115:1279-1285.

27. Drani M, Tong L, Gazzard G. et al.Outdoor activity and myopia in Singapore teenage children. Br J Ophthalmol. 2009; 93:997-1000.

28. Guo $\mathrm{Y}$, Liu LJ, Xu L, et al. Outdoor activity and myopia among primary students in rural and urban regions of Beijing. Ophthalmology. 2013; 120:277-283.

29. You QS, Wu LJ, Duan JL. et al. Factors associated with myopia in school children in China: the Beijing childhood eye study. PLoS One. 2012; 7(12):e52668.

30. Wu PC, Tsai CL, Wu HL, Yang YH, Kuo HK. Outdoor activity during class recess reduces myopia onset and progression in school children. Ophthalmology. 2013; 120:1080-1085.

31. French AN, Morgan IG, Burlutsky G, Mitchell P, Rose KA. Prevalence and 5to 6- year incidence and progression of myopia and hyperopia in Australian schoolchildren. Ophthalmology. 2013; 120:1482-1491.

32. Zadnik K, Mutti DO, Friedman NE. et al. Ocular predictors of the onset of juvenile myopia. Invest Ophthalmol Vis Sci. 1999; 40:1936-1945.

33. Panrapee F, Supaporn T, Pasuree S, Prinda S. Accuracy of noncycloplegic refraction in primary school children in southern Thailand. J Med Assoc Thai. 2009;92:806-812.

34. Wu LJ, You QS, Duan JL, et al. Prevalence and Associated Factors of Myopia in High-School Students in Beijing. PLoS ONE; 10(3): e0120764. 